\title{
MODELING AND MEASURING SITUATION AWARENESS IN THE INFANTRY \\ OPERATIONAL ENVIRONMENT
}

\section{CONTENTS}

Page

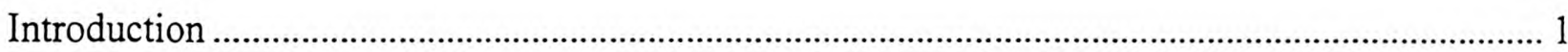

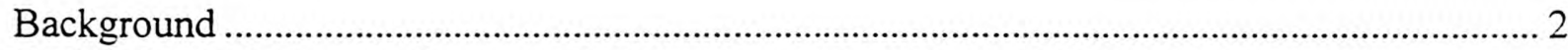

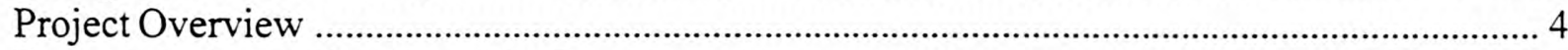

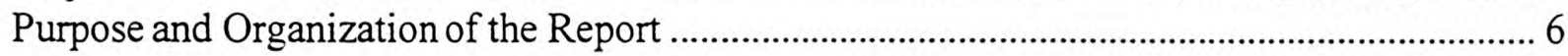

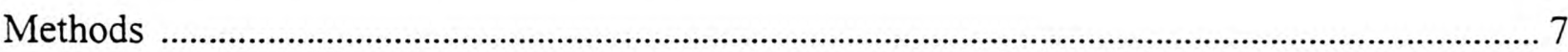

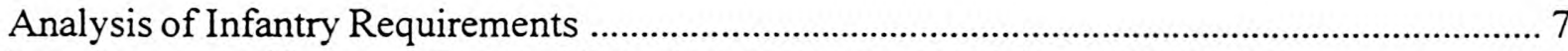

Development of Infantry-Focused Situation Awareness Model .............................................. 8

Review of Situation Awareness Measurement Approaches ................................................. 10

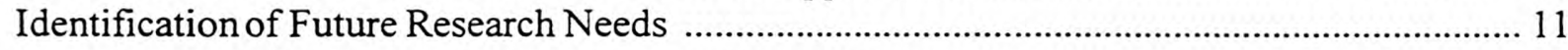

Infantry Requirements Related to Situation Awareness ....................................................... 11

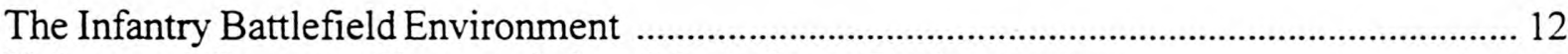

Unique and Common Characteristics of the Infantry Environment ...................................... 14

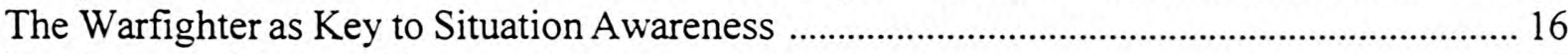

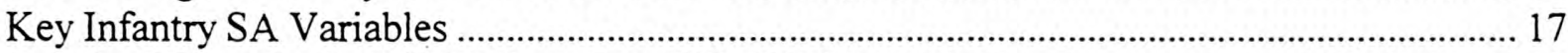

Levels of Organization (Brigade to Squad/Soldier) .................................................................. 19

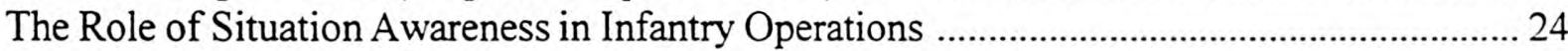

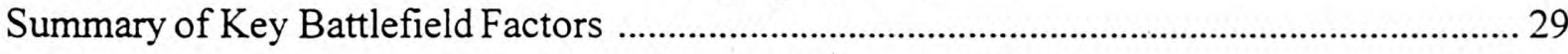

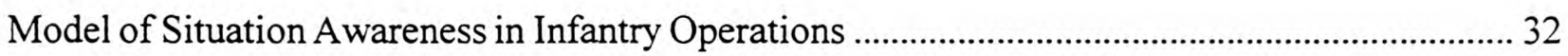

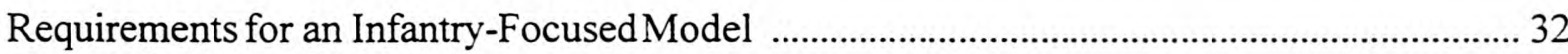

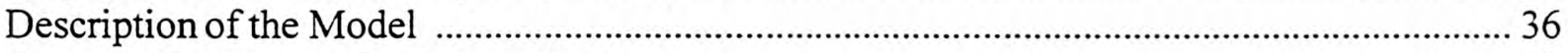

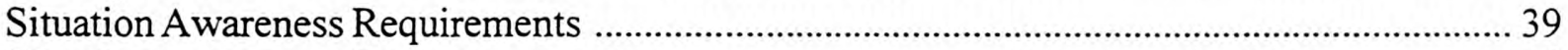

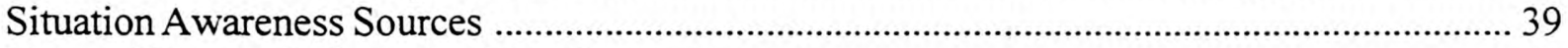

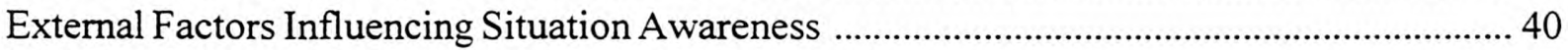

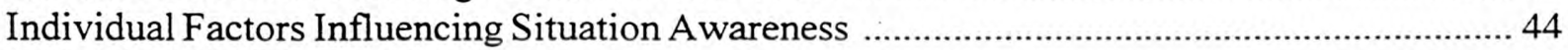

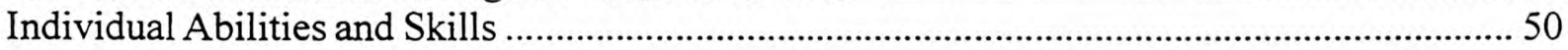

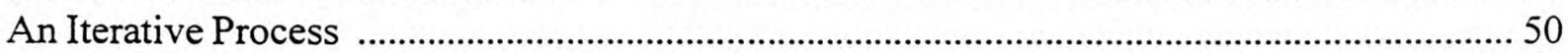

Army Mechanisms for Achieving Situation Awareness ......................................................... 51

Situation Awareness in Multiple-Distributed Teams in Infantry Operations ............................ 53

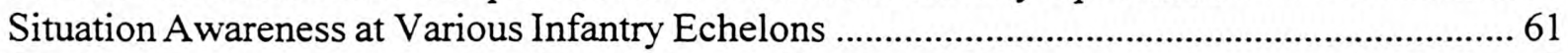

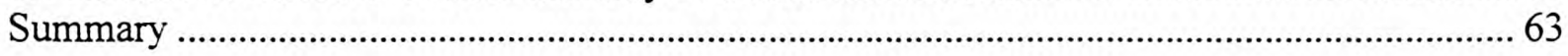

